\title{
Determinants of Quality of Life among Rural Elderly Population in Khonkean Province of Thailand
}

\author{
Korravarn Yodmai, Ratana Somrongthong, Ramesh Kumar
}

\section{ABSTRACT}

OBJECTIVE: To explore the factors influencing the quality of life among the elderly population of rural Thailand.

METHODOLOGY: This cross-sectional study was conducted at Khon Kean Province, Thailand in one month of time period. Non-probability sampling technique was adopted by including four hundred twenty-eight elderly people age of sixty and above in this study. They were invited through available list with health department and willing participants were enrolled after taking their written consent. Those who were sick during the time of study were excluded. The quality of Life (QOL) was assessed through WHOQOL-OLD questionnaire. Chi-square was used to analyze the factors associated with the QOL in aging. Study was ethically approved from Mahidol University Thailand.

RESULTS: A total of 428 elderly with a mean age of 78 years $( \pm 4)$ were included in this study. The results found that over $361(84 \%)$ of the elderly had moderate QOL, around 59(13.8\%) of respondents replied they had a good quality of life and $6(1.6 \%)$ had fair QOL. Factors influencing the QOL among the elderly included marital status, most were married (62.9\%), followed by divorced, widowed and single (37.1\%), sufficient income $(69.2 \%)$, savings, sufficient money for health care services, and needed to work.

CONCLUSION: Study concluded that the factors like marital status, sufficient income, savings, healthcare services are influencing the quality of life among aging in Thailand.

KEYWORDS: Quality of Life, Elderly Population.

This article may be cited as: Yodmai K, Somrongthong R, Kumar R. Determinants of Quality of Life among Rural Elderly Population in Khonkean Province of Thailand. J Liaquat Uni Med Health Sci. 2018;17(03):180-4. doi: 10.22442/jlumhs.181730574

\section{INTRODUCTION}

In the existing literature, several studies have shown that physical well-being is a key element influencing the quality of life (QOL), according to health conditions and independence, and it affects the ability to perform daily living activities in general ${ }^{1-4}$. In addition, external factors such as social security, housing, and work also affect our life. Some studies have tackled the issue of social support influencing life satisfaction in aging rural communities reporting that living alone, disability and limited activity could predict life satisfaction level ${ }^{2,5}$. In related studies focusing on social support and the quality of life among the elderly, economic downturn was found to affect lifestyle, well being, and limitations ${ }^{6,7}$. Economic deficits occur when individuals are unemployed and it results in low financial status of children, the unemployed and aging individuals. In addition, other studies have focused on important environmental factors affecting aging communities ${ }^{7,8}$. Economic factors are also important determiners of the QOL and well being among aging individuals during retirement. After retiring, aging individuals become economically vulnerable because they have limited savings to survive in a capitalistic society where every service or product requires money. Economic deficit refers to poor financial status because of unemployment. When people have an economic deficit, they also experience less freedom in financial matters that may be related to economic decisions and level of life satisfaction. Both children and retired elderly produce less than they consume increasing economic deficits, In contrast, working age adults produce more through the labor force but consume less affording them greater freedom from the economic deficit ${ }^{2,4,9}$.

The number of aging population is still growing in Thai population. Hence, there is dire need to investigate the background of aging Thais, explore related concepts of economic status among older adults and research strategies to reduce financial burden of aging population. The objectives of this study was to explore the determinants influence the QOL among aging people living in rural areas in Thailand is important to understand and effectively prepare for Thai aging society in the 21 st century.

\section{METHODOLOGY}

This cross-sectional descriptive one month study was conducted in a rural community, in KhonKaen 
Province, northeast Thailand in June, 2015. Non-probability sampling was adopted by taking all the willing participants from the list of registered elderly population available with health department in concerned area. Hence, 428 elderly community members aged 60 and above years of age irrespective to any gender were finally recruited for this study. However, those who were sick at the time of study were excluded from this study. Data was collected by well-trained researchers and measured by the WHOQOL-OLD questionnaire with 24 items with scores ranging from 24 to 120 . According to the score, QOL was divided in three levels; high QOL is considered when the score lies between 90-120, moderate QOL means the score lies in 60-89 and low QOL applies when score comes 25 to 59 Socioeconomic factors included like; sex, education, marital status, income, employment status, health care expense and saving for medical care. In order to assess the QOL and its facets like; sensory ability, Autonomy, past/present/future activities, ability, social participation, death dying and Intimacy facet were also checked. The factors influence the quality of life was analyzed using Chi-square and the p-value was accepted 0.05 by using SPSS version 20. Ethical approval was obtained from the Human Ethics Committee of Mahidol University, Thailand, and all respondents provided written informed consent in accordance with the Declaration of Helsinki and confidentiality of the participants were ensured.

\section{RESULTS}

A total of Four Hundred Twenty Eight elderly with a mean age of 78 years $( \pm 4)$ participated in this study and their average monthly income ranged from less than 30 USD. Over $50 \%$ of respondents had no savings. Concerning attitudes of working, $60 \%$ reported they needed a job. However, $40 \%$ replied they don't want work. Chi-square test revealed that marital status, income, healthcare expense, saving, healthcare expenses, personal need to work after retirement, personal attitude toward working among elderly person and QOL. However, sex, education, income, current profession and QOL were shown not significant (Table I).

This study found that most of the elderly had a moderate QOL $(84.3 \%)$, followed by high $\mathrm{QOL}$ $(13.8 \%)$ and $1.9 \%$ of low.QOL regarding the death and dying facet was the highest, followed by intimacy $(31.1 \%)$, sensory ability (24.1\%), autonomy $(19.9 \%)$, past-present-future activity (17.5\%) and social participation (17.5\%). When looking at the lowest QOL in each facet, death and dying facet $(18.9 \%)$ obtained a higher QOL score than autonomy and intimacy $(14.0 \%)$ followed by social participation
(12.4\%), past-present-future activity ability (11.7\%) and sensory ability $(2.8 \%$ as shown in Table II.

Table I: SOCIO-DEMOGRAPHIC CHARAC TERISTICS AND FACTORS INFLUENCING THE QUALITY OF LIFE AMONG THE ELDERLY $(n=428)$

\begin{tabular}{|c|c|c|c|}
\hline \multicolumn{2}{|c|}{ Variables } & Numbers & $x 2 p$ \\
\hline \multirow{2}{*}{ Sex } & Male & $170(39.7 \%)$ & \multirow{2}{*}{0.24} \\
\hline & Female & $258(60.3 \%)$ & \\
\hline \multirow[b]{2}{*}{ Marital Status } & Married & $270(62.9 \%)$ & \multirow[b]{2}{*}{$0.02^{*}$} \\
\hline & $\begin{array}{l}\text { Window/ Single/ } \\
\text { Divorced }\end{array}$ & $158(37.1 \%)$ & \\
\hline \multirow{3}{*}{ Education } & Primary Level & $390(90.7 \%)$ & \multirow{3}{*}{0.60} \\
\hline & $\begin{array}{l}\text { Higher level edu- } \\
\text { cation }\end{array}$ & $12(3.0 \%)$ & \\
\hline & No schooling & $26(6.3 \%)$ & \\
\hline \multirow{3}{*}{$\begin{array}{l}\text { Monthly In- } \\
\text { come }\end{array}$} & Less than 30 US\$ & $344(80.4 \%)$ & \multirow{3}{*}{0.07} \\
\hline & 30 to 59 US\$ & $61(14.3 \%)$ & \\
\hline & 60 US\$ and above & $23(5.4 \%)$ & \\
\hline \multirow{4}{*}{$\begin{array}{l}\text { Source of } \\
\text { Income }\end{array}$} & Social security & $321(75 \%)$ & \multirow{4}{*}{$<0.05^{\star}$} \\
\hline & Family members & $54(12.4 \%)$ & \\
\hline & Personal income & $44(10.3 \%)$ & \\
\hline & $\begin{array}{l}\text { Others such as } \\
\text { relatives }\end{array}$ & $9(2.3 \%)$ & \\
\hline \multirow[t]{2}{*}{ Saving } & Sufficient & $297(69.2 \%)$ & \multirow{2}{*}{$<0.01^{* *}$} \\
\hline & Insufficient income & $131(30.8 \%)$ & \\
\hline \multirow{2}{*}{$\begin{array}{l}\text { Working } \\
\text { status }\end{array}$} & Working & $301(69.6 \%)$ & \multirow{2}{*}{0.53} \\
\hline & Not working & $127(29.4 \%)$ & \\
\hline \multirow{2}{*}{$\begin{array}{l}\text { Current Pro- } \\
\text { fession }\end{array}$} & Agriculturalists & $405(94.6 \%)$ & \multirow{2}{*}{$<0.01^{*}$} \\
\hline & Business & $23(5.4 \%)$ & \\
\hline \multirow{3}{*}{$\begin{array}{l}\text { Healthcare } \\
\text { Expenses }\end{array}$} & No expenses & $233(54.4 \%)$. & \multirow{3}{*}{$0.01^{*}$} \\
\hline & Minimum expenses & $130(30.4 \%)$ & \\
\hline & Maximum expenses & $65(15.2 \%)$ & \\
\hline \multirow{2}{*}{$\begin{array}{l}\text { Personal need } \\
\text { to work after } \\
\text { retirement }\end{array}$} & Employed & $301(69.6 \%)$ & \multirow{2}{*}{$<0.01^{*}$} \\
\hline & Not employed & $127(29.4 \%)$ & \\
\hline \multirow{2}{*}{$\begin{array}{l}\text { Personal atti- } \\
\text { tude towards } \\
\text { work }\end{array}$} & Want work & $256(60 \%)$ & \multirow{2}{*}{$<0.01^{* *}$} \\
\hline & Don't want work & $172(40 \%)$ & \\
\hline
\end{tabular}

QOL = Quality of Life using total quality of life score ${ }^{*} P$-value accepted $0.05,{ }^{* *} P$-value accepted 0.01 


\section{TABLE II: NUMBER AND PERCENT OF THE QUALITY OF LIFE AND ITS FACETS AMONG ELDERLY IN THIS STUDY}

\begin{tabular}{|l|r|r|r|}
\hline \multirow{2}{*}{ Variables } & \multicolumn{3}{|c|}{ Number (\%) } \\
\cline { 2 - 4 } & \multicolumn{1}{|c|}{ Low } & Moderate & \multicolumn{1}{c|}{ High } \\
\hline TQOL & $6(1.6 \%)$ & $361(84.3 \%)$ & $59(13.8 \%)$ \\
\hline SAB & $12(2.8 \%)$ & $313(73.1 \%)$ & $103(24.1 \%)$ \\
\hline AUT & $60(14.0 \%)$ & $283(66.1 \%)$ & $85(19.9 \%)$ \\
\hline PPF & $50(11.7 \%)$ & $299(69.9 \%)$ & $79(18.5 \%)$ \\
\hline SOP & $53(12.4 \%)$ & $300(70.1 \%)$ & $75(17.5 \%)$ \\
\hline DAD & $81(18.9 \%)$ & $180(42.1 \%)$ & $167(39.0 \%)$ \\
\hline INT & $60(14.0 \%)$ & $235(54.9 \%)$ & $133(31.1 \%)$ \\
\hline
\end{tabular}

${ }^{*} T Q O L=$ total quality of life, $S A B=$ sensory ability facet, $A U T=$ Autonomy facet, $P P F=$ past, present, and future activities ability facet, $S O P=$ Social Participation facet, $D A D=$ death and dying facet, INT= Intimacy facet

\section{DISCUSSION}

This study aimed to examine potential economic factors mediating the QOL among aging people in a rural community. Our finding showed that the QOL among the aging was rated at a moderate level, similar to related studies found in the central region ${ }^{8}$, Study found in the southern region ${ }^{9}$. Most of Thais elderly (84\%) in rural sitting have moderate QOL, this finding supported policy makers to understand situation of elderly in rural setting and create the strategies for improving the elder life. Elderly in rural setting was limited to access the public services such as public transportation and having an inquired the number of healthcare professional when compared with urban setting.

Moreover, this study found that marital status, sufficient income, healthcare expenses, savings, prospects of healthcare expenses and their savings, personal need to work during retirement and attitude toward work for the elderly were significantly related to QOL among the aging. In term of social capital, an ascribe status of individual is difference. Social class was defined in difference aspect of society, the individual factors such as wealth, educational, occupational, family background, and races were used to categorize the difference classes. While, those factors affected the quality of life in previous studies that showed that elderly who have no national pension had poor QOL level in Korea ${ }^{10}$. While, low wealth and low household income was a factor related with poor QOL. However, not only individual financial factor influence to the quality of life in elderly but their family income also affected to their QOL. Previous studies reported that financial support from offspring was significantly associated with QOL among the aging and filial duty provided an important role to improve the QOL, especially in an Asian aging community 4,10 . In contrast, no significant difference was found regarding the associations between sex, education level, average income, current working status and sufficient life expenses and QOL. However, this study found financial support from family was unassociated with QOL because aging people were financially supported by government welfare that it was difference with a pension of another countries included South Korea and Singapore. This study found that the greatest source of income in the study population was elderly allowance to differing from the study, that reported the major source of income among aging individuals was subsidies from children and the second source was their own work ${ }^{11}$.

Factors influencing QOL in this study included marital status, sufficient income, healthcare expense, savings, prospects of healthcare expense and their savings, personal need to work during retirement and attitude toward job for the elderly. Study found that marital status also affected personal finances. Single older women had worse finance problems than men ${ }^{12}$. However, still living with a spouse was a predictor of successful aging ${ }^{13}$. However, it remained unknown whether couples living together had the same or a different QOL. However, Co-residential arrangement or living arrangement is indicative of the family structure and family functions, but living arrangement situation in Thailand is changed. Many elderly live alone with their couple or live with vulnerable persons such as children, HIV infected persons, and disable person, this situation affected to the later life of elderly. Co-resident will be meaningful if it was not just an accountable. With society support concept, family members is a main resource of support for an individual. Limitation of family support will affected to a vulnerable person. Magnitude of society on supporting in elderly needs to be exploring. In addition, marital status in aging populations implies a meaning in terms of caring (including caring with or without child).Caring within a couple is another issue of living later life. Several studies indicated female elderly provided care for their male couple was higher compared male couple cared female that it needs to assess in further, whether caring situation within family affected to the quality of life in elderly ${ }^{11,12}$.

In this study, several economic factors included sufficiency of income, healthcare expense, savings, prospects of health care expense and savings influencing QOL. Our finding indicated over one-half 
of aging people still needed to work. However, almost $50 \%$ had a good attitude toward aging work while $52 \%$ of them disagreed with encouraging aging adults to work. We could observe barriers to work among aging people did not involve financial problems. Working in aging people still question for policy makers, several countries confront with decrease the working people but it's not possible that aging workers will be benefit for solving this problem. Aging working performance is an issue and still discussed. Which job are the appropriate for retirees is discussing. In opposite, an attitude of aging on senior working still unclear, over a half of aging disagreed. In ASEAN countries, an attitude of society still accepted that young family members need to look after their parent ${ }^{12}$. An abandoned parent is a humiliated for that family or child. During economic cries, working in aging people will help increase wealth in family. However, working in aging still question for policy and law, accepted in community, and attitude of an aging in developing counties, especially in Thailand and it needs to understand before to follow proper guideline.

No significant difference was found regarding associations between education level, average income, current working status and sufficient life expense and QOL in this study. However, achieved status such as education and working, income, and sufficient life expensewas closely associated with QOL in previous studies ${ }^{9,14-16}$, however, in our study the educational level was reported were quite low and is inconsistent with these findings because our study participants belongs to rural areas of Thailand that might affects on their qualification level.Generally, Thais have had limited access to school for several decades; over $90 \%$ of aging adults obtained an only primary education that may have limited the finding in this study. The standard education for children in Thailand was poor. All children encouraged completing their primary school (Grad 4 only), and to access the higher education for children with poverty family is limited. This limitation affected to literate in aging people. Higher proportion of primary attended among aging in rural setting may affected the differently association from other studies ${ }^{9,10,11}$.

In addition, the average monthly income may have been less than actual income that aging adults earned or they may receive financial support or material support from children living in the same village. Therefore, the average income of participants was 30US\$ in this study which affecting on their QOL. Our finding are similar to several studies found that an income of aging in China does not relate to their quality of life ${ }^{16,17}$. Study in Bangladesh also found that poor economic status of aging family related with an aging $\mathrm{QOL}$ in Bangladesh $^{18}$. Income and family supportmight play a vital role in QOL among elderly population.

\section{LIMITATIONS}

This study had several limitations; first, being a cross-sectional study limited the outcome. This research focused only on one point of time and only in a rural community that may not be generalized to urban setting. Secondly, self-reported economic factors might create bias. However, the income of respondents was ensured through the evidence. Even though, this study was trained a data collectors to collected those information, but this self reported data-subjective data, may affected to this study. Tracking data was not possible due to the ethical issue. The limitation of chi-square analysis was that it can present only relationships of the variables and outcomes, but cannot show the magnitude of the outcome. However, in depth information needs to conduct a research in the further.

\section{CONCLUSION}

This study concluded that most of aging people in Thailand have a moderate QOL level. Factors like; their monthly income was only 30 USD and some did not receive financial support from their families. Working after retirement is an important issue and society has to decide at what age it should be, or how to hire aging people using the law.

\section{ACKNOWLEDGEMENT}

This work support in a part by Faculty of Graduate Studies, and China Medical Board (CMB) scholar, Faculty of Public Health, Mahidol University for publication funding.

\section{REFERENCES}

1. Rejeski WJ, Mihalko SL. Physical activity and quality of life in older adults. J Gerontol A Biol Sci Med Sci. 2001;56 (2):23-35.

2. Banjare $P$, Dwivedi R, Pradhan J. Factors associated with the life satisfaction amongst the rural elderly in Odisha, India. Health Qual Life Outcomes. 2015;13:201.

3. Sanoski CA. Clinical, economic, and quality of life impact of atrial fibrillation. J Manag Care Pharm. 2009;15(6):4-9.

4. Chen Y, Hicks A, While AE. Quality of life and related factors: a questionnaire survey of older people living alone in Mainland China. Qual Life Res. 2014;23(5):1593-602.

5. Onunkwor OF, Al-Dubai SA, George PP, Arokiasamy $\mathrm{J}$, Yadav $\mathrm{H}$, Barua $\mathrm{A}$, et al. A cross-sectional study on quality of life among the elderly in non-governmental organizations' elderly 
homes in Kuala Lumpur. Health Qual Life Outcomes. 2016;14:6.

6. Hubbard RE, Goodwin VA, Llewellyn DJ, Warmoth K, Lang IA. Frailty, financial resources and subjective well-being in later life. Arch Gerontol Geriatr. 2014;58(3):364-9.

7. Read S, Grundy E, Foverskov E. Socio-economic position and subjective health and well-being among older people in Europe: a systematic narrative review. Aging Ment Health. 2016;20 (5):529-42.

8. Yodmai K, Phummarak S, Sirisuth JC, Kumar R, Somrongthong R. Quality of life and fear of falling among an aging population in semi rural, thailand. J Ayub Medical Coll, Abbottabad. 2015;27(4):7714.

9. Hongthong $\mathrm{D}$, Somrongthong $\mathrm{R}$, Ward $\mathrm{P}$. Factors influencing the quality of life (QOL) among Thai older people in a rural area of Thailand. Iranian J Public Health. 2015;44(4):479-85.

10. Ju YJ, Han KT, Lee TH, Kim W, Kim J, Park EC. Does relationship satisfaction and financial aid from offspring influence the quality of life of older parents?: a longitudinal study based on findings from the Korean longitudinal study of aging, 20062012. Health Qual Life Outcomes. 2016;14 (1):108.

11. Knodel J, Chayovan N. Older Persons in Thailand: A demographic, social and cconomic profile. Ageing International. 2008;33(1):3-14.

12. Keith PM. Finances of unmarried elderly people over time. Int J Aging Hum Dev. 1988;26(3): 211-23.

13. Roos NP, Havens B. Predictors of successful aging: a twelve-year study of Manitoba elderly. Am J Public Health. 1991;81(1):63-8.

14. Raggi A, Corso B, Minicuci N, Quintas R, Sattin D, De Torres $L$, et al. Determinants of quality of Life in ageing populations: results from a cross-sectional study in Finland, Poland and Spain. PLoS ONE. 2016;11(7):e0159293.

15. Paskulin L, Vianna L, Molzahn AE. Factors associated with quality of life of Brazilian older adults. International nursing review. 2009;56 (1):109-15.

16. Wang S, Li L, Li J. Study on the quality of life among the elderly in the rural and pastoral districts in Baotou city. Zhonghua liuxingbingxue zazhi. 2001;22(3):205-7.

17. Zhao Y, Hu C, Feng F, Gong F, Lu S, Qian Z, et al. Associations of self-neglect with quality of life in older people in rural China: a cross-sectional study. Int Psychogeriatr. 2017:1-12.

18. Nilsson J, Rana AK, Kabir ZN. Social capital and quality of life in old age: results from a cross-sectional study in rural Bangladesh. J Aging Health. 2006;18(3):419-34.

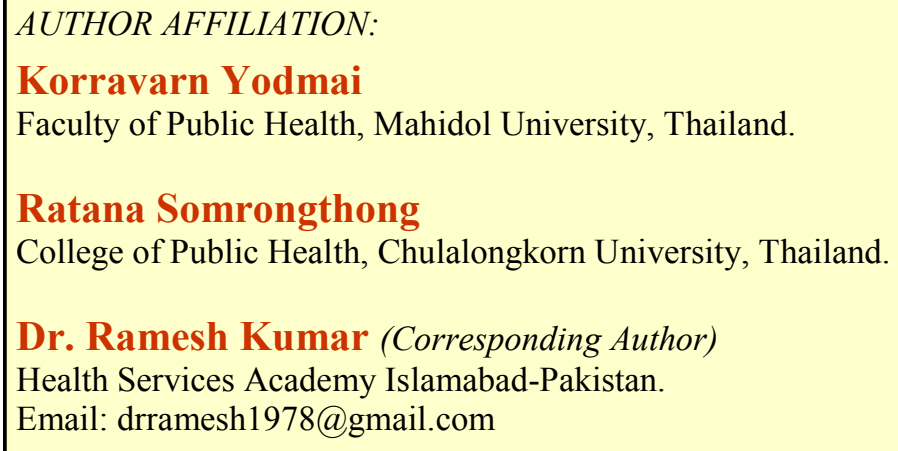

